\title{
Geometri Bintang Berotasi pada Keadaan Kritis
}

\author{
Iwan Setiawan* dan Muhammad Farchani Rosyid \\ Kelompok Riset Kosmologi, Astrofisika, \\ dan Fisika Matematika,Jurusan Fisika FMIPA UGM \\ Jl. Babasari, Yogyakarta
}

\begin{abstract}
Intisari
Konfigurasi kesetimbangan mekanis pada bintang-bintang berotasi ditelaah melalui model Roche. Pada kajian ini bintang diperlakukan sebagai benda tegar, sedangkan geometrinya ditentukan berdasarkan persamaan ekipotensial. Kedaan kritis suatu bintang ditentukan berdasarkan ketiadaan gaya gravitasi total yang mengimbangi tekanan termodinamis. Dalam hal ini terdapat dua kemungkinan, percepatan gravitasi efektifnya lenyap atau batas Edington-nya terlampui. Telah ditentukan penampang membujur bintang-bintang berotasi dari berbagai massa dan kecepatan sudut.
\end{abstract}

KATA KUNCI: rotasi bintang, keadaan kritis, kecepatan kritis, luminositas

\section{PENDAHULUAN}

Bintang mengalami rotasi seperti juga Bumi. Diketahui bahwa akibat rotasi, jejari katulistiwa Bumi 21,4 km lebih panjang dibanding jejari kutubnya [1]. Bintang yang memiliki rotasi tinggi, jejari katulistiwanya bahkan dapat mencapai 1,5 jejari polar [2]. Ini menunjukkan bahwa rotasi cukup berpengaruh pada bintang. Mekanisme kesetimbangan pada bintang yang berotasi sudah dipelajari sejak lama, beberapa model telah dikembangkan. Contohnya adalah model Mclaurin, yang menganggap kerapatan bintang yang tetap dan model Roche, yang beranggapan sebaliknya (kerapatan yang tidak tetap). Terdapat perbedaan yang cukup mencolok antara kedua model ini. Dalam model Mclaurin, konfigurasi kesetimbangan tampak memipih untuk rotasi yang tinggi. Pada rotasi yang sangat tingi model ini akan seperti piringan tipis yang tak hingga. Nilai maksimum kecepatan sudut pada model ini (dianggap rotasi benda tegar) adalah $\Omega_{\max }^{2}=0,4494 \mathrm{G} \rho$ [1], kenyataannya akan terjadi ketidakstabilan sebelum mencapai batas kecepatan angular ini. Pada model Roche dengan $\Omega$ seragam (bintang dianggap sebagai rotasi benda tegar), gambaran kesetimbangan juga akan tampak memipih untuk mencapai perbandingan antara jejari kutub dan jejari equatorial $2 / 3$. Kecepatan sudut maksimum pada model ini yaitu $0,7215 \mathrm{G} \bar{\rho}$, dengan $\bar{\rho}$ adalah kerapatan rata-rata. Pendekatan dengan model Roche biasanya lebih banyak digunakan karena lebih dekat kepada fakta yang ada.

\section{TINJAUAN PUSTAKA}

\section{A. Kesetimbangan Hidrostatik pada Rotasi Benda Tegar}

Jika ditinjau dari kerangka acuan yang berotasi bersama bintang, persamaan Navier-Stokes berbentuk

*E-MAIL: iwanphysics@gmail.com

$$
\begin{aligned}
\frac{d \mathbf{v}^{\prime}}{d t} & =\frac{d \mathbf{v}}{d t}-\frac{1}{\rho} \nabla P+\nu \nabla^{2} \mathbf{v}^{\prime}-\Omega \times(\Omega \times r) \\
& -\frac{d \Omega}{d t} \times \mathbf{r}-2 \Omega \times \mathbf{v}
\end{aligned}
$$

dengan $\nu$ viskositas, $\mathrm{P}$ tekanan, dan $\Omega$ kecepatan sudut. Jika sistem dianggap berada dalam kesetimbangan hidrostatik, dan viskositas diabaikan (dianggap sangat kecil), serta kecepatan sudut dianggap sama di semua tempat di bintang (rotasi benda tegar), maka akan didapatkan persamaan,

$$
0=-\nabla \Phi-\frac{1}{\rho} \nabla P-\Omega \times\left(\Omega \times r^{\prime}\right)-2 \Omega \times v^{\prime}
$$

dengan $-\nabla \Phi$ percepatan gravitasi. Jika $V_{s}$ didefinisikan sebagai potensial sentrifugal, dengan

$$
V=-\frac{1}{2} \Omega^{2} \varpi^{2}
$$

dengan $\varpi=r \sin \theta$ jarak titik yang ditinjau dari sumbu rotasi maka didapat persamaan

$$
\frac{1}{\rho} \nabla P=-\nabla \Psi=\mathbf{g}_{e f}
$$

dengan

$$
\begin{aligned}
\Psi(r, \theta) & =\Phi(r)+V(r, \theta) \\
& =-\frac{G M_{r}}{r}-\frac{1}{2} \Omega^{2} r^{2} \sin ^{2} \theta
\end{aligned}
$$

adalah potensial efektif yang memenuhi persamaan Poisson $\nabla^{2} \Psi=4 \pi G \rho-2 \Omega^{2}$, dengan $M_{r}$ massa bagian bintang yang berada di dalam bola berjejari $r$ yang berpusat di pusat bintang. Karena berlakunya Pers.(4), bintang dikatakan dalam keadaan Barotropik [2], yakni, daerah dengan nilai potensial yang sama (ekipotensial) memiliki tekanan yang sama, $P=P(\Psi)$. 
Permukaan bintang adalah daerah ekipotensial, yakni $\Psi=$ tetapan. Andaikan kita tinjau sebuah bintang dengan massa total $\mathrm{M}$ dan $\mathrm{R}(\theta)$ jejari bintang itu pada kolatitud $\theta$. Karena gaya sentrifugal di daerah kutub bernilai nol, maka potensial pada kutub bintang itu adalah $-\mathrm{GM} / \mathrm{R}_{p}$, dengan $\mathrm{R}_{p}$ jejari kutub bintang. Oleh karenanya, nilai potensial di berbagai tempat di permukaan bintang itu adalah

$$
\frac{G M}{R_{p}}=-\frac{G M}{R(\theta)}-\frac{1}{2} \Omega^{2} R(\theta)^{2} \sin ^{2} \theta
$$

Jika $\mathbf{e}_{r}$ dan $\mathbf{e}_{\theta}$ merupakan vektor satuan dalam arah radial dan arah bujur, maka vektor percepatan gravitasi efektif pada permukaan bintang dari Pers.(5) dapat dituliskan sebagai

$$
\begin{aligned}
\mathbf{g}_{e f} & =\left[-\frac{G M}{R(\theta)^{2}}+\Omega^{2} R(\theta) \sin ^{2} \theta\right] \mathbf{e}_{r} \\
& +\left[\Omega^{2} R(\theta) \sin \theta \cos \theta\right] \mathbf{e}_{\theta}
\end{aligned}
$$

\section{B. Teorema von Zeipel dan Faktor Eddington}

Teorema von Zeipel menyatakan hubungan antara fluks radiasi pada kolatitud $\theta$ di permukaan bintang yang berotasi dengan percepatan gravitasi efektif lokal [3]. Jika kita tinjau bintang yang berotasi seperti rotasi benda tegar, fluks radiasi dapat dituliskan sebagai

$$
\mathbf{F}(\Omega, \theta)=-\chi \nabla T(\Omega, \theta)
$$

dengan

$$
\chi=\frac{4 a c T^{3}}{3 \kappa \rho}
$$

Karena bintang berada dalam keadaan barotropik, maka

$$
\begin{aligned}
\mathbf{F}(\Omega, \theta) & =-\frac{d T}{d P} \nabla P(\Omega, \theta) \\
& =-\rho \chi \frac{d T}{d P} \mathbf{g}_{e f}
\end{aligned}
$$

Dengan demikian, dari hubungan antara luminositas bintang dan fluks radiasi, didapatkan

$$
\mathbf{F}(\Omega, \theta)=-\frac{L}{4 \pi G M_{*}} \mathbf{g}_{e f}(\Omega, \theta)
$$

dengan

$$
M_{*}=M\left(1-\frac{\Omega^{2}}{2 \pi G \rho_{m}}\right)
$$

dan $\rho_{m}$ rapat massa rata-rata bahan pada permukaan bintang itu.

Pada bintang yang berotasi, percepatan gravitasi total bintang merupakan penjumlahan beberapa percepatan : percepatan gravitasi murni, percepatan sentrifugal, dan percepatan oleh tekanan radiasi [3]. Hal ini dinyatakan dalam persamaan berikut

$$
\begin{aligned}
\mathbf{g}_{t o t} & =\mathbf{g}_{e f}+\mathbf{g}_{r a d} \\
& =\mathbf{g}_{g r}+\mathbf{g}_{r o t}+\mathbf{g}_{r a d}
\end{aligned}
$$

dengan $\mathbf{g}_{\text {rad }}$ diberikan oleh

$$
\mathbf{g}_{\text {rad }}=\frac{1}{\rho} \nabla P_{r a d}=\frac{\kappa(\theta) \mathbf{F}}{c}
$$

Faktor $\kappa(\theta)$ adalah kekedapan bahan pada kolatitud $\theta$. Dengan memanfaatkan Pers.(11) dan (13), persamaan berikut didapatkan

$$
\mathbf{g}_{t o t}=\mathbf{g}_{e f}\left[1-\frac{\kappa(\theta) L(P)}{4 \pi c G M_{*}}\right]
$$

Pada persamaan ini efek rotasi muncul pada $\mathbf{g}_{e f}$ dan pada ungkapan di dalam kurung. Jika kita tinjau batas fluks secara lokal, yaitu keadaan dengan $\mathbf{g}_{t o t}=0$ [3], maka $\mathbf{g}_{\text {rad }}=\mathbf{g}_{e f}$. Batas fluks, oleh karena itu, diberikan oleh

$$
\mathbf{F}_{l i m}(\theta)=-\frac{c}{\kappa(\theta)} \mathbf{g}_{e f}(\theta)
$$

Dari persamaan ini, jika faktor Eddington lokal $\Gamma_{\gamma}(\theta)$ didefinisikan sebagai nisbah (rasio) antara besarnya fluks sebenarnya dengan besarnya fluks batas lokal, maka didapatkan

$$
\Gamma_{\Omega}(\theta)=\frac{\kappa(\theta) L(P)}{4 \pi c G M\left(1-\frac{\Omega^{2}}{2 p i G \rho_{m}}\right)}
$$

Jika tidak bintang tidak mengalami rotasi (yakni jika $\Omega$ bernilai 0 ), maka $\Gamma_{\Omega}(\theta)$ akan sama dengan faktor Edington Global $\Gamma$. Pers. (15), selanjutnya, dapat ditulis sebagai

$$
\mathbf{g}_{t o t}=\mathbf{g}_{e f}\left[1-\Gamma_{\gamma}(\theta)\right]
$$

Persamaan ini mengungkapkan bahwa pada bintang yang berotasi, percepatan gravitasi total dipengaruhi oleh percepatan gravitasi efektif $\mathbf{g}_{e f}$ (yang melibatkan ungkapan tentang kecepatan rotasi bintang) dan oleh luminositas bintang.

\section{HASIL DAN PEMBAHASAN}

\section{A. Keadaan Ambang (kritis) Pertama}

Melalui ungkapan Pers. (18), keadaan ambang (critical state) dapat diperkirakan. Pada keadaan kritis ini percepatan gravitasi total lenyap sehingga tidak ada lagi percepatan atau gaya yang mengimbangi tekanan termal dari dalam bintang. Akibatnya, bahan-bahan bintang akan lari (buyar). Hal ini tentu saja mengakibatkan Pers. (18) akan mempunyai dua akar, yaitu $\mathbf{g}_{e f}=0$ atau $\Gamma_{\Omega}(\theta)=1$. Keadaan ini mengakibatkan adanya batas (limit) tertentu pada kecepatan rotasi bintang, selain bergantung pada beberapa parameter lain seperti massa bintang dan jejari bintang. Keadaan $\mathbf{g}_{\text {tot }}=0$ juga akan memberikan adanya batas pada luminositas bintang sebagaimana dijelaskan di atas, yang disebut sebagai 
Batas Eddington [5]. Keadaan ambang $\mathbf{g}_{e f}=0$ akan dinamakan keadaan ambang pertama, sedangkan keadaan pada $\Gamma_{\Omega}(\theta)=1$, disebut keadaan ambang kedua.

Keadaan ambang $\mathbf{g}_{\text {tot }}=0$ menurut Pers.(7) diperoleh hanya pada wilayah katulistiwa $(\theta=\pi / 2)$. Keadaan ini memberikan ungkapan

$$
\Omega_{k r i t}^{2}=\frac{G M}{R_{e, k r i t}^{3}}
$$

dengan $R_{e, k r i t}$ jeari-jari bintang di katulistiwa ketika keadaan kritis itu. Jika faktor $\mathrm{f}$ didefinisikan sebagai nisbah

$$
f=\frac{R_{e}}{R_{p}}
$$

antara jari-jari katulistiwa dan jari-jari kutub untuk sembarang kecepatan sudut, maka secara umum didapat

$$
\frac{\Omega}{\Omega_{k r i t}}=\left(\frac{2}{3}\right)^{3 / 2}\left(\frac{R_{p, k r i t}}{R_{p}}\right)^{3 / 2}\left(\frac{2(f-1)}{f^{3}}\right)^{1 / 2}
$$

Dengan pendekatan $R_{p, k r i t}=R_{p}$, yakni tidak ada perubahan pada jari-jari kutub, didapat

$$
\frac{\Omega}{\Omega_{\text {krit }}}=\left(\frac{3}{2}\right)^{3 / 2}\left(\frac{2(f-1)}{f^{3}}\right)^{1 / 2}
$$

Dari persamaan terakhir ini tampak bahwa $f=3 / 2$ pada saat $\Omega=\Omega_{\text {krit }}$.

Jika $\nu$ kecepatan singgung di katulistiwa, maka

$$
\frac{v}{v_{k r i t}}=\left(\frac{\Omega}{\Omega_{k r i t}} 2(f-1)\right)^{1 / 3}
$$

\section{B. Geometri Bintang pada Berbagai Nilai Kecepatan Sudut}

Kita tinjau kembali persaman permukaan bintang sebagai daerah equipotensial, yakni Pers.(6). Persamaan tersebut dapat dituliskan sebagai

$$
R(\theta)^{3}-\frac{2 G M}{\Omega^{2} R_{p} \sin ^{2} \theta} R(\theta)+\frac{2 G M}{\Omega^{2} \sin ^{2} \theta}=0
$$

Persamaan ini memperlihatkan bahwa jejari bintang yang berotasi, sebagai fungsi sudut kolatitud, memenuhi persamaan polinom pangkat tiga yang bergantung kepada berbagai parameter : tetapan gravitasi $(\mathrm{G})$, massa bintang $(\mathrm{M})$, jejari polar $\left(\mathrm{R}_{p}\right)$, serta parameter kecepatan rotasi bintang itu sendiri $(\Omega)$. Jika jejari bintang $(\mathrm{R}(\theta))$ dievaluasi pada semua sudut kolatitud maka akan didapatkan bentuk penampang bintang yang berotasi.

Memanfaatkan beberapa data yang menyebutkan tentang parameter-parameter di atas, penampang membujur sebuah
TABEL I: Parameter bintang berotasi dengan massa $1 \mathrm{M} \mathrm{[6]}$

\begin{tabular}{lcccccc}
\hline \hline $10^{4} \Omega$ & 0 & 1,0 & 3,0 & 4,0 & 4,6 & 4,6254 \\
\hline$\alpha$ & 0,000 & 0,020 & 0,205 & 0,451 & 0,903 & 1,0018 \\
$R_{e} / R_{p}$ & 1,000 & 1,010 & 1,108 & 1,237 & 1,470 & 1,5198 \\
$V_{e} k / s$ & 0 & 64 & 201 & 288 & 381 & 395 \\
$\mathrm{~L} / \mathrm{L}_{\odot}$ & 0,712 & 0,705 & 0,650 & 0,599 & 0,561 & 0,5595 \\
$\mathrm{R}_{e} / R_{\odot}$ & 0,914 & 0,919 & 0,964 & 1,035 & $1,, 189$ & 1,2261 \\
$\mathrm{R}_{p} / R_{\odot}$ & 0,914 & 0,909 & 0,871 & 0,837 & 0,809 & 0,8067 \\
\hline \hline
\end{tabular}

bintang dengan kecepatan rotasi tertentu akan dapat digambarkan dengan terlebih dahulu menyelesaikan persamaan pangkat tiga untuk jejari bintang, Pers.(24). Pers.(24) dapat ditulis dalam bentuk

$$
R(\theta)^{3}-A R(\theta)+B=0
$$

dengan

$$
A=-\frac{2 G M}{\Omega^{2} R_{p} \sin ^{2} \theta}
$$

dan .

$$
B=\frac{2 G M}{\Omega^{2} \sin ^{2} \theta}
$$

Persamaan ini merupakan persamaan polinom pangkat tiga dengan paramater yang lebih sederhana, yang jika diselesaikan dengan metode Newton-Raphson dan dengan menggunakan data pada Tabel I, akan didapatkan jejari bintang $\mathrm{R}(\theta)$ pada kolatitud $\theta$. Perhitungan dengan cara itu menghasilkan Tabel II, dengan

$$
G=3,8 \times 10^{-7} \frac{R^{3}}{M s^{2}}
$$

Dari Tabel II diperoleh tampang bujur bintang tersebut pada kuadran I pada koordinat kartesian, sebagaimana diperlihatkan pada Gambar 1. Hasil perhitungan untuk bintang bermassa $1 \mathrm{M}$ dalam berbagai kecepatan sudut rotasi diberikan oleh Gambar 2. Untuk Bintang $1 \mathrm{M}$ dengan kecepatan sudut rotasi $\Omega=4,6 \times 10^{-4} \mathrm{rad} / \mathrm{s}$ didapatkan bentuk penampang bujur yang melancip sepanjang

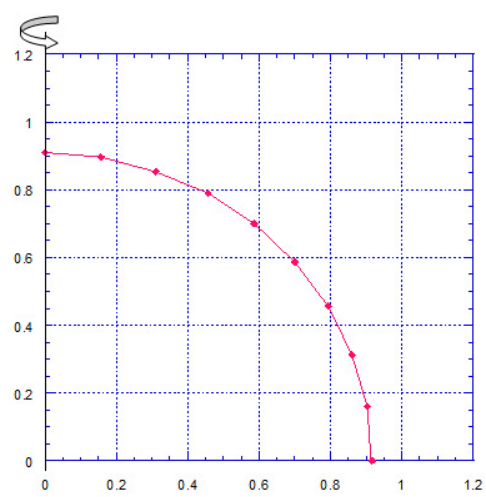

Gambar 1: Tampang bujur bintang berotasi $1 \mathrm{M}$ dengan $\Omega=10^{-4}$ $\mathrm{rad} / \mathrm{s}$. 
TABEL II: Jejari bintang $1 \mathrm{M}$ dengan $\Omega 10^{-4} \mathrm{rad} / \mathrm{s}$

\begin{tabular}{ccccccccc}
\hline \hline$\Omega^{2}$ & $\mathrm{R}_{p}$ & $\theta$ & $\sin ^{2} \theta$ & $\mathrm{A}$ & $\mathrm{B}$ & $\mathrm{R}$ & $\mathrm{X}$ & $\mathrm{Y}$ \\
\hline $1,00 \mathrm{E}-08$ & 0,909 & 10 & 0,03014 & 2774,2798 & 2521,8294 & 0,9092 & 0,1578 & 0,8954 \\
$1,00 \mathrm{E}-08$ & 0,909 & 20 & 0,11696 & 714,8213 & 649,7726 & 0,91 & 0,3112 & 0,8551 \\
$1,00 \mathrm{E}-08$ & 0,909 & 30 & 0,25 & 334,4334 & 304,0000 & 0,9112 & 0,4556 & 0,7891 \\
$1,00 \mathrm{E}-08$ & 0,909 & 40 & 0,41317 & 202,3602 & 183,9454 & 0,9127 & 0,5867 & 0,6991 \\
$1,00 \mathrm{E}-08$ & 0,909 & 50 & 0,5867 & 142,4926 & 129,5257 & 0,9143 & 0,7004 & 0,5870 \\
$1,00 \mathrm{E}-08$ & 0,909 & 60 & 0,74996 & 111,4844 & 101,3393 & 0,9158 & 0,7931 & 0,4579 \\
$1,00 \mathrm{E}-08$ & 0,909 & 70 & 0,88302 & 94,6844 & 86,0682 & 0,9171 & 0,8618 & 0,3136 \\
$1,00 \mathrm{E}-08$ & 0,909 & 80 & 0,96983 & 86,2092 & 78,3642 & 0,9179 & 0,9039 & 0,1593 \\
$1,00 \mathrm{E}-08$ & 0,909 & 90 & 1 & 83,6084 & 76,0000 & 0,9182 & 0,9182 & 0,0000 \\
\hline \hline
\end{tabular}

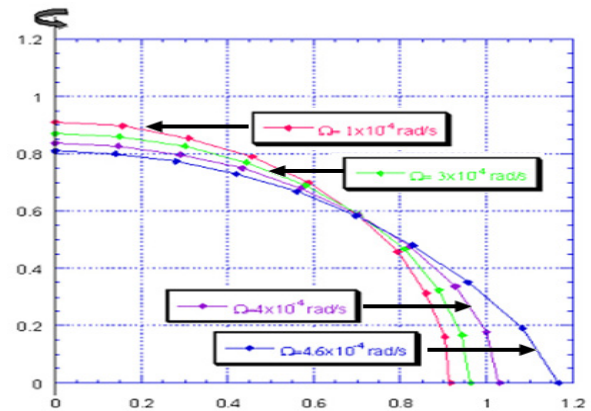

(a). $1 \mathrm{M}$

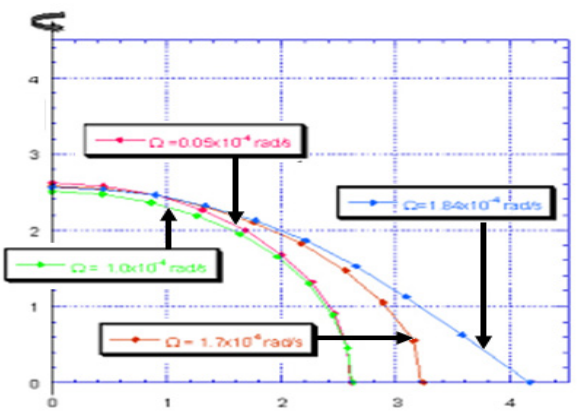

(b). $5 \mathrm{M}$

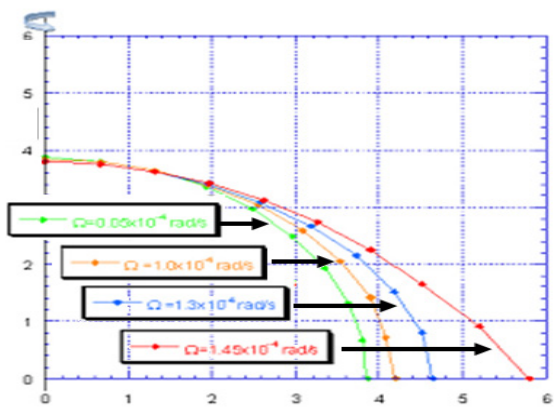

(c). $10 \mathrm{M}$

Gambar 2: Penampang bintang untuk beberapa nila $\Omega$

lingkar katulistiwa, kecepatan rotasi ini merupakan kecepatan yang mendekati kecepatan sudut kritis. Terlihat bahwa peningkatan kecepatan sudut rotasi akan menyebabkan terjadinya perubahan penampang bintang, sebagaimana diperlihatkan pada Gambar 2.

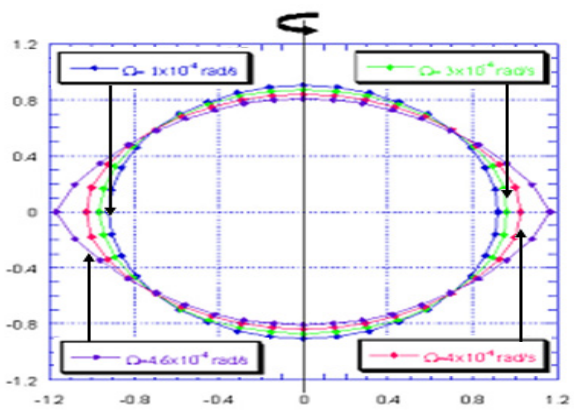

(a). $1 \mathrm{M}$

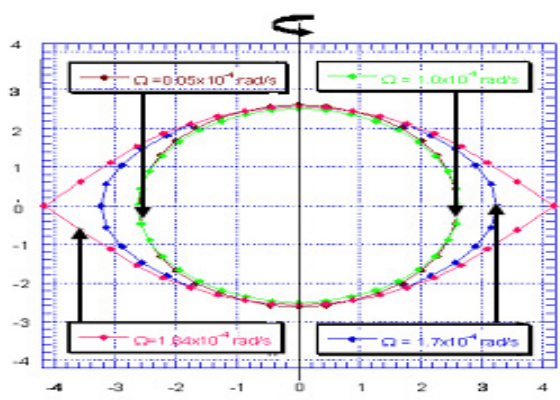

(b). $5 \mathrm{M}$

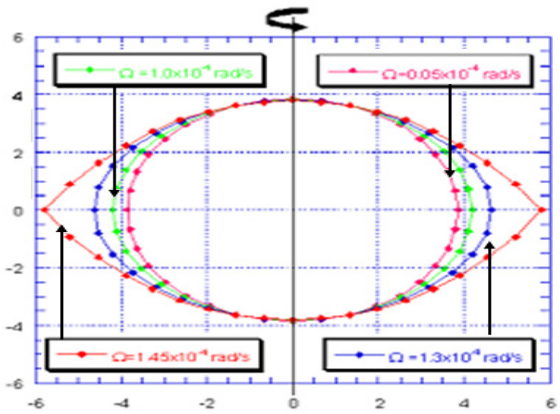

(c). $10 \mathrm{M}$

Gambar 3: Penampang bintang untuk beberapa nila $\Omega$

Jika digambarkan secara keseluruhan, dengan prinsip kesetangkupan antar kuadran didapatkan Gambar 3. Dari beberapa gambar diatas terlihat bahwa, meningkatnya kecepatan rotasi akan merubah kesetimbangan bintang, yang ditandai dengan penurunan jejari polar dan meningkatnya jejari katulis- 
tiwa. Pada Gambar 2, didapatkan bentuk penampang bujur bintang yang semakin melancip di katulistiwa karena seiring peningkatan kecepatan sudut rotasi. Penampang bintang yang paling melancip pada ujung-ujungnya ini merupakan penampang bintang dengan kecepatan rotasi yang sudah mencapai kecepatan kritis, ini dapat dibuktikan dengan nilai perbandingan antara jejari equatorial dan jejari polar yang telah mencapai $3 / 2$.

\section{Geometri Bintang Pada Kecepatan Sudut Ambang}

Meningkatnya kecepatan rotasi akan memengaruhi kesetimbangan bintang. Jika kecepatan rotasi mencapai nilai ambang, maka jejari bintang dikatakan juga pada keadaanambang. Persamaan jejari bintang pada kecepatan ambang dapat dituliskan menjadi

$$
R_{k}(\theta)^{3}-\frac{2 G M}{\Omega_{k}^{2} R_{p, k} \sin ^{2} \theta} R_{k}(\theta)+\frac{2 G M}{\Omega_{k}^{2} \sin ^{2} \theta}=0
$$

dengan $R_{k}(\theta)$ jejari jejari bintang pada keadaan kritis, k kecepatan sudut bintang pada keadaan ambang, serta $R_{p, k}$ jejari polar pada keadaan ambang. Jika kita gunakan ungkapan pada Pers.(19), maka Pers.(25), dapat dituliskan menjadi

$$
R_{k}(\theta)^{3}-\frac{27 R_{p, k}^{2}}{4 \sin ^{2} \theta} R_{k}(\theta)+\frac{27 R_{p, k}^{3}}{4 \sin ^{2} \theta}=0
$$

Persamaan ini diselesaikan dengan metode yang sama dengan yang sebelumnya, dengan terlebih dahulu menentukan nilai $R_{p, k}$. Ungkapan untuk $R_{p, k}$ didapatkan dari Pers.(19) dan bantuan data-data yang diperoleh dari [4]. Hasil-hasil perhitungan untuk beberapa variasi massa bintang, pada kuadran I koordinat kartesian seperti pada Gambar 4. Jika digambarkan pada semua kuadran, didapatkan Gambar 5.

Dari beberapa gambar terlihat bahwa pada keadaan kritis, dengan kecepatan rotasi bintang yang juga berada pada kecepatan ambang, bentuk penampang bintang akan memipih, dengan ujung-ujung pada daerah khatulistiwa berbentuk lancip. Keadaan seperti ini disebabkan karena pada keadaan kritis. Di daerah katulistiwa gravitasi efektif yang bernilai nol, sehingga material dalam bintang yang sebelumnya berada dalam kesetimbangan hidrostatik (tekanan hidrostatik diimbangi oleh gravitasi), akan menuju keluar, karena tidak ada lagi gaya gravitasi yang menahannya.

\section{Keadaan Ambang Kedua}

Keadaan Ambang kedua didapatkan ketika nisbah Eddington local, $\Gamma_{\Omega(\theta)}$, pada Pers.(18) bernilai 1. Sehingga Pers.(17) dapat dituliskan menjadi

$$
\frac{\kappa(\theta) L(P)}{4 \pi c G M}=1-\frac{\Omega^{2}}{2 \pi G \rho_{m}}
$$

Melalui persamaan ini, dapat ditunjukkan bahwa luminositas pada bintang yang berotasi bergantung pada suku kedua ruas kanan Pers.(28), sehingga kecepatan rotasi bintang

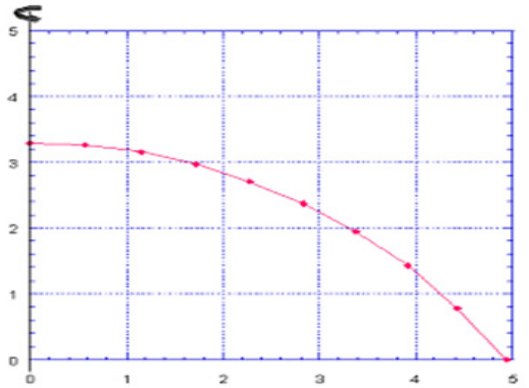

(a). $9 \mathrm{M}, \Omega_{k}=1,684 \cdot 10^{-4} \mathrm{rad} / \mathrm{s}$

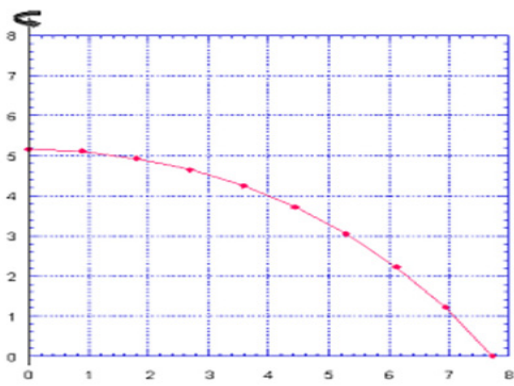

(b). $20 \mathrm{M}, \Omega_{k}=1,28 \cdot 10^{-4} \mathrm{rad} / \mathrm{s}$

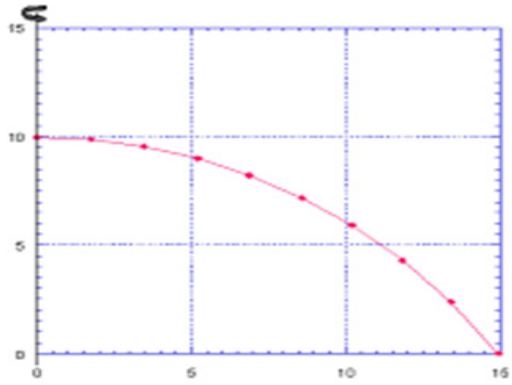

(c). $60 \mathrm{M}, \Omega_{k}=8,26 \cdot 10^{-5} \mathrm{rad} / \mathrm{s}$

Gambar 4: Penampang bintang untuk beberapa nila $\Omega$

memenuhi

$$
\frac{\Omega^{2}}{2 \pi G \rho_{m}}<1
$$

Dengan menggunakan ungkapan $\rho_{m}=\mathbf{M} / \mathrm{V}$, dapat ditunjukkan bahwa

$$
\Omega^{2}<\frac{2 \pi G M}{V}
$$

Pers.(30) menunjukkan bahwa, untuk menjamin keberlangsungan luminositas pada bintang yang berotasi, maka kecepatan rotasi bintang tersebut harus lebih kecil dari hasil kali antara besaran $2 \pi$ dengan tetapan gravitasi umum $\mathrm{G}$ dan kerapatan rata-rata permukaan bintang yang ditinjau. Oleh karena itu, dapat disimpulkan bahwa kecepatan rotasi bintang juga memengaruhi luminositas atau kecerlangan bintang, nilai kecepatan rotasi ini dibatasi oleh suku kedua ruas kanan Pers.(29). Inilah yang disebut sebagai keadaan kritis kedua. 


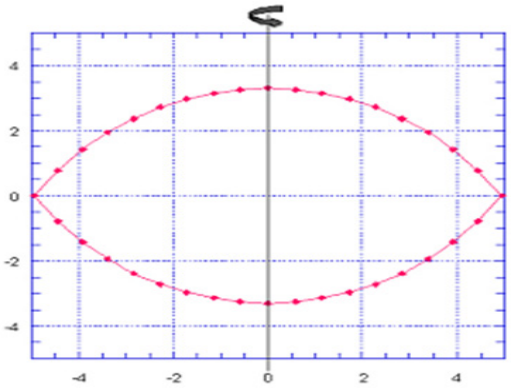

(a). $9 \mathrm{M}, \Omega_{k}=1,684 \cdot 10^{-4} \mathrm{rad} / \mathrm{s}$

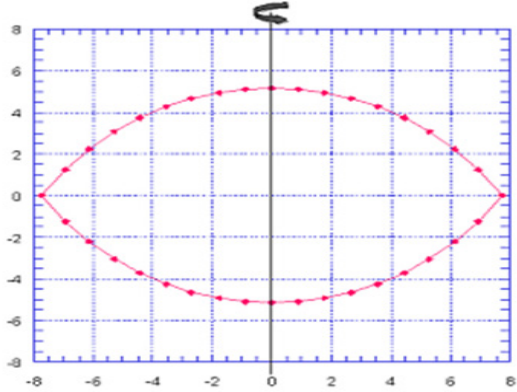

(b). $20 \mathrm{M}, \Omega_{k}=1,28.10^{-4} \mathrm{rad} / \mathrm{s}$

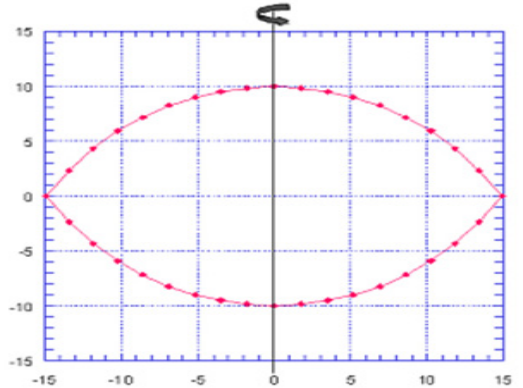

(c). $60 \mathrm{M}, \Omega_{k}=8,26 \cdot 10^{-5} \mathrm{rad} / \mathrm{s}$

Gambar 5: Penampang bintang untuk beberapa nila $\Omega$

\section{SIMPULAN}

Kecepatan sudut rotasi bintang berpengaruh besar pada bentuk tampang bujur bintang itu. Terdapat dua macam ambang bagi kecepatan sudut rotasi bintang. Tampang bujur bintang pada kecepatan ambang pertama sangat khas. Jika kecepatan sudut rotasi bintang melampaui kecepatan ambang pertama, maka kesetimbangan hidrostatis pada bintang akan dilanggar, yakni tidak ada lagi kesetimbangan hidrostatik. Keadaan ambang kedua dicapai pada saat kecepatan rotasi bintang sebanding dengan $2 \mathrm{GM} / \mathrm{V}$. Jika kecepatan kritis pada keadaan kritis kedua dilampaui, maka bintang akan "padam", yakni luminositasnya nol.
[1] Maeder, A., Physics, Formation and Evolution of Rotating Stars (Springer Verlag Berlin Heidelberg, Germany. Pp. 22-80, 2009).

[2] Ekstrom, S, Meynet G, Maeder, A, Barblan F., Evolution Towards the Critical Limit and the Origin of Be Stars, arXiv:0711.1735v1 (2008).

[3] Maeder, A, Meynet, G., The Eddington and $\Omega$-Limits, the rotational mass loss for $O B$ and $L B V$ stars, Astronomy \& Astrophysics, 361, 159-166 (2000).

[4] Meynet, G, Maeder, A., The Computational Method and Inhibit- ing Effect of the -Gradient, Astronomy \& Astrophysics, 321, 465-476 (1997).

[5] Meynet, G., Physics of Rotation in Stellar Models, arXiv:0801.2944v1 (2008).

[6] Roxburgh, I.W., 2-Dimensional Models of Rapidly Rotating Stars, Uniformly Rotating Zero Age Main Sequence Stars. Astronomy \& Astrophysics, 428, 171-179 (2004). 